\title{
A confounding of conditioned suppression in passive avoidance: ECS effects
}

\author{
ABRAHAM A. SPEVACK AND MILTON D. SUBOSKI \\ QUEEN'S UNIVERSITY, KINGSTON, ONTARIO
}

Shock administered either contingent upon or between bar presses reduced bar press rates. Extinction to situational cues and a series of seven ECSs starting $24 \mathrm{~h}$ after shock raised bar press rates, indicating that conditioned suppression occurs in passive avoidance conditioning.

In the one-trial passive avoidance paradigm punishment of a highly probable response results in decreased rates and increased latencles of response. Presumably, Ss have learned to avoid the noxious stimulation by not responding. However, decreased response rates may be produced by an alternative procedure-conditioned suppression-where a freezing response conditioned to the situational cues competes with the previously emitted response. Since both conditioned suppression and passive avoidance procedures have identical behavioral consequences, reduced rates of responding after noxious treatment cannot be explained solely in terms of either paradigm.

Moreover, electroconvulsive shock (ECS) may have different temporal effects on behavior resulting from conditioned avoidance and conditioned suppression (Chorover \& Schiller, 1966). Their results emphasize the point that if inferences are to be drawn concerning the amnestic properties of ECS, the behavioral consequences of the conditioned suppression paradigm must be distinguished from those of one-trial passive avoidance.

No such distinction is apparent in the numerous studies which purport to define the time course of memory consolidation (e.g., Heriot \& Coleman, 1962; Weissman, 1964). In the experiments by Heriot \& Coleman (1962) and Welssman (1964), rats given a single shock contingent upon a bar press showed subsequent reduced bar press rates. Estes (1944), however, has shown that rats shocked between rather than for bar presses also showed reduced response rates. Furthermore, rats subsequently exposed to the apparatus but not permitted to bar press showed recovery of bar press rates. These results suggest that shock delivered in the bar pressing situation can produce conditioned suppression as well as passive avoidance. The two studies reported here investigated the possibility that contingent shock delivered in a one-trial passive avoidance paradigm gives rise to substantial elements of conditioned suppression. If such a possibility could be confirmed, it would support the possibility that the long term amnestic effects of ECS could be due to an alleviation of conditioned suppression rather than to an effect on memory consolidation.

\section{Procedure}

\section{EXPERIMENT 1}

The 49 male albino rats, $23 \mathrm{~h}$ food deprived throughout the experiment, were trained to bar press in a Grason-Stadler conditioning box, and then given six $10 \mathrm{~min}$ daily sessions on a continuous reinforcement schedule. During the seventh session, after $5 \mathrm{~min}$ of responding, $21 \mathrm{Ss}$ were given a $4 \mathrm{~mA}$ shock for $0.5 \mathrm{sec}$ contingent upon a bar press (Contingent groups). An additional 21 rats were given equal shock after retrieving a food pellet and before starting the next bar press, but otherwise independent of their behavior (Noncontingent groups). Seven rats (Normal Controls) were not shocked. The contingent and noncontingent shockgroups were each divided into three groups of seven Ss. All Ss were removed from the box and had ECS electrodes attached to their ears within 2.5-5.0 min after shock. All Ss received pseudo-ECS except one contingent and one noncontingent group which received a $42 \mathrm{~mA}$ ECS for $0.5 \mathrm{sec}$. Two additional groups, one contingent and one noncontingent shock, were given $10 \mathrm{~min}$ exposure to the conditioning apparatus with the bar removed on each of the following two days. All other Ss were placed in a black wooden box for equal periods of time. On the third day after avoidance training, all Ss were given a 5 min test session with the bar present.

\section{Results and Discussion}

Table 1 shows the mean number of bar presses during the test session as a percentage of the number of bar presses during the first 5 min of the avoidance training session. The table displays only slight overall differences in bar press rates produced by contingent and noncontingent shock. This is supported by an analysis of variance which yielded an $F$ ratio of less than 1 for the effect due to contingent vs noncontingent shock. Although differences between the contingent and noncontingent shock appear among the treatment groups, the variance due to the interaction with treatment groups produced an $F$ ratio of only 1.07. The analysis did indicate that the differences produced by the treatment conditions were significant ( $F=9.44, \mathrm{df}=2 / 36, \mathrm{p}<.01$ ). A Duncan range test showed that the groups which received shock followed by ECS pressed the bar signifi-

Table 1 Mean responding on test day as a percentage of responding on treatment day

\begin{tabular}{lccr}
\multicolumn{4}{c}{ responding on treatment day } \\
\hline & Control & Exposure & ECS \\
Contingent Shock & 21.23 & 43.71 & 93.00 \\
Noncontingent Shock & 32.22 & 59.61 & 73.69 \\
Normal & 113.44 & & \\
\hline
\end{tabular}


cantly more frequently on posttreatment test than did Ss that received shock alone or shock followed by extinction sessions $(p<.05)$. Although Table 1 shows that Ss that had undergone exposure pressed more than those that received shock alone, the difference just missed the $5 \%$ level of slgnificance.

A comparison of the means of the Normal Control Ss and the shock alone groups indicates that both contingent and noncontingent shock produced substantial decrements in bar pressing rates. The decrement produced by noncontingent shock seems extremely unlikely to have resulted from passive avoidance, but rather to be a conditioned suppression effect. The fact that exposure to the conditioning apparatus in the absence of the bar effected a partial recovery of bar press rates for both contingent and noncontingent shock groups suggests that contingent shock also produced at least part of the decrement by conditioned suppression effects. Time spent in the conditioning box with the bar removed can be expected to extinguish a suppression response conditioned to situational cues. An avoidance response, however, would only extinguish through unpunished occurrence of the response which the absence of the bar prevented.

\section{EXPERIMENT 2}

The second experiment was intended to further investigate the hypothesis that the reduced bar press rates produced by contingent shock is due to a substantial degree to conditioned suppression. Brady and associates (e.g., Brady \& Hunt, 1951) have developed a technique for alleviating conditioned suppression by following conditioned suppression training with a series of ECSs beginning $24 \mathrm{~h}$ after training. The $24 \mathrm{~h}$ learningECS interval effectively precludes the possibility that the effect of the ECSs could be on memory processes. The present experiment used Brady's procedure on rats given contingent shock for bar pressing. If only passive avoidance is produced by contingent shock, an ECS series should have little effect. However, if contingent shock produces conditioned suppression, rats receiving an ECS series would show bar press rates significantly greater than untreated rats.

\section{Procedure}

Training was as in Experiment 1 except that five rather than six training sessions were used. Of the three groups of 10 albino rats each, two groups were given treatments identical to the Contingent Shock alone, i.e., a single shock contingent upon a bar press, and the Contingent Shock-ECS, 1.e., contingent shock followed by ECS within $5 \mathrm{~min}$, groups of Experiment 1. The third group received contingent shock alone with a series of ECSs beginning $24 \mathrm{~h}$ later. The Ss received three ECSs at least $1 \mathrm{~h}$ apart on the first posttreatment day, and two on each of the second and third days. All other Ss were given a similar number of pseudo-ECSs. Testing took place on the fifth posttreatment day. Results and Discussion

Number of test day bar presses expressed as a percentage of treatment day responses resulted in a mean of $23.4 \%$ for the Shock Control Ss, 60\% for the ECS Series group, and $91.2 \%$ for the Single ECS group. Analysis indicated that the differences in posttreatment bar pressing rates between the Shock Control and ECS Series groups $(t=3.99, \mathrm{df}=17, \mathrm{p}<.001)$ and the ECS Series and Single ECS groups $(t=2.33$, df $=17, p<.05)$ were significant.

The recovery of bar press rates produced by a series of ECSs starting $24 \mathrm{~h}$ after a learning trial supports the conclusion that shock contingent upon bar pressing results in conditioned suppression. The fact that greater alleviation of conditioned suppression occurs with a series of 21 rather than seven ECSs (Brady \& Hunt, 1951) suggests that the amount of conditioned suppression produced by passive avoidance training may be even greater than the present results indicate.

The present results raise the implication that shock administration may produce conditioned suppression in any avoidance conditioning situation. If Chorover \& Schiller (1966) are correct in postulating different temporal effects of ECS for conditioned avoidance and conditioned suppression, tests of memory consolidation using ECS following one-trial passive avoidance learning are invalid because of the confounding of conditioned suppression in the passive avoidance situation. We suggest that if memory consolidation theory is to be tested using ECS, it must be in a one-trial discriminated avoidance paradigm, where correct choices can be used as an indicator of memory.

References

BRADY, J. V., \& HUNT, H. F. A further demonstration of the effects of electro-convulsive shock on a conditioned emotional response. $J$. comp. physiol. Psychol, 1951, 44, 204-209.

CHOROVER, S. L., \& SCHILLER, P. H. Reexamination of prolonged retrograde amnesia in one-trial learning. J. comp. physiol. Psychol, $1966,61,3441$.

ESTES, W. K. An experimental study of punishment. Psychol. Monogr., 1944, 57 (Whole No. 263).

HERIOT, J. T., \& COLEMAN, P. D. The effect of electroconvulsive shock on retention of a modified "one-trial" conditioned avoidance. J. comp. physiol, Psychol., 1962, 55, 1082-1084.

WEISSMAN, A. Retrograde amnesia effect of supramaximal electroconvulsive shock on one-trial acquisition in rats: A replication. $J$. comp. physiol. Psychol, 1964, 57, 248-250.

Note

1. We thank Bruce Osborne and Lynne Hepburn for assistance. This research was supported by a grant from the Committee on Scientific Research of Queen's University and National Research Council of Canada grant APA 160. This research was presented at the Canadian Psychological Association meeting, Ottawa, 1967. 